\title{
PENERAPAN MEDIA PEMBEMBELAJARAN KOGNITIF DALAM MATERI PERSAMAAN GARIS LURUS MENGGUNAKAN VIDEO DI ERA 4.0
}

\author{
Fine Siwi ${ }^{1}$, Nicky Dwi Puspaningtyas ${ }^{2}$ \\ Universitas Teknokrat Indonesia ${ }^{1,2}$ \\ finesiwi1708@gmail.com
}

\begin{abstract}
Received: Mei 2020
Accepted: Juni 2020

Abstract

At this time thinking creativity is low in the world of education. To improve creative thinking patterns urgently, as educators must have ways to improve them. Learning mathematics can be done only through the medium of learning mathematics. Audio-visual media, is a type of media used in learning activities with hearing and vision in one process or activity. Messages and information that can be channeled through this media can consist of verbal and nonverbal messages that depend on the sight whether hearing. In this 4.0 era, students are required to be better able to think cognitive in learning. Fully creative thinking including in the current era is needed. However, at this time creative thinking in the world of education is low. To improve the importance of creative thinking patterns, as educators who already have a way to improve it by using learning media. Therefore the material explanation method is made using video-based media to facilitate students in understanding the material and also improve their cognitive abilities. This research can prove through video-based learning media can be an effective method in improving students' cognitive abilities.
\end{abstract}

Published: Juni 2020

Keywords: Media, Video, Cognitive

\begin{abstract}
Abstrak
Pada saat ini berfikir kreatif sangatlah rendah di dunia pendidikan. Untuk meningkatkan pola berfikir kreatif sangatlah penting, sebagai seorang pendidik sudah seharusnya memiliki cara untuk meningkatkannya. Kemampuan berpikir dapat ditingkatkan dalam pembelajaran matematika yang bukan hanya mengenai angka Salah satu caranya juga yaitu dengan melalui media pembelajaran matematika. Media audio-visual, adalah jenis media yang digunakan dalam kegiatan pembelajaran dengan melibatkan pendengaran dan penglihatan sekaligus dalam satu proses atau kegiatan. Pesan dan informasi yang dapat disalurkan melalui media ini dapat berupa pesan verbal dan nonverbal yang mengandalkan baik penglihatan maupun pendengaran. Pada era 4.0 ini, siswa dituntut untuk lebih dapat berfikir kognitif dalam pembelajaran. Berfikir secara kreatif termasuk dalam kognitif pada era ini sangatlah diperlukan. Namun, pada saat ini berfikir kreatif sangatlah rendah di dunia pendidikan. Untuk meningkatkan pola berfikir kreatif sangatlah penting, sebagai seorang pendidik sudah seharusnya memiliki cara untuk meningkatkannya yaitu dengan melalui media pembelajaran. Oleh karena itu dibuat metode penjelasan materi belajar menggunakan media berbasis video untuk memudahkan siswa dalam memahami materi dan juga meningkatkan kemampuan kognitifnya. Penelitian ini dapat membuktikan bahwa melalui media pembelajaran berbasis video dapat menjadi metode yang efektif dalam peningkatan kemampuan kognitif siswa.
\end{abstract}

Kata Kunci: Media, Video, Kognitif 
Sitasi artikel ini:

Siwi, F. \& Puspaningtyas, N.D. (2020). Penerapan Media Pembembelajaran Kognitif dalam Materi Persamaan Garis Lurus menggunakan

Video Di Era 4.0. Jurnal Ilmiah Matematika Realistik, 1(1), 7-10

\section{PENDAHULUAN}

Dalam dunia pendidikan di era 4.0 ini, pesertadidik di tuntut untukdapat berfikir kreatif. Menurut Yusuf (2011) berpikir kreatif (Creative thinking) adalah kemampuan berpikir dengan cara-cara baru dan menemukan pemecahan masalah secara unik. Kemampuan berpikir bukan berpikir konvergen (yang menghasilkan satu jawaban benar), tetapi berpikir divergen (yang menghasilkan banyak jawaban untuk pertanyaan yang sama). Seperti yang dinyatakan oleh Maskar dan Anderha (2019), siswa sebaiknya berpikiran terbuka dan memahami bahwa solusi dari tiap masalah itu bisa bervariasi.

Pada saat ini berfikir kreatif sangatlah rendah di dunia pendidikan. Untuk meningkatkan pola berfikir kreatif sangatlah penting, sebagai seorang pendidik sudah seharusnya memiliki cara untuk meningkatkannya. Kemampuan berpikir dapat ditingkatkan dalam pembelajaran matematika yang bukan hanya mengenai angka (Puspaningtyas, 2019). Salah satu caranya juga yaitu dengan melalui media pembelajaran matematika. Menurut Gagne dalam Sadiman (2006), media adalah berbagai jenis komponen dalam lingkungan siswa yang dapat merangsang untuk belajar. Sementaraitu, Briggs dalam Sadiman (2006) berpendapat bahwa media adalah segala alat fisik yang dapat menyajikan pesan merangsang siswa untuk belajar.

Menurut Rohani (1997), pemilihan dan pemanfaatan media perlu memperhatikan kriteria, tujuan serta media hendaknya menunjang tujuan intruksional yang telah dirumuskan. Validitas tepat dan berguna bagi pemahaman bahan yang dipelajari dan keadaan peserta didik, mampu memperdaya pola pikir dan daya tangkap peserta didik serta dari besar kecil nya kelemahan peserta didik perlu pertimbangan. Menurut Chalid (2017) Media pembelajaran memiliki banyak ragam, salah satunya adalah media audio-visual. Sejalan dengan itu, Saputra dan Febriyanto (2019) menyatakan bahwa perkembangan teknologi dapat dijadikan solusi sebagai media pembelajaran untuk menarik perhatian siswa.

Pembelajaran yang monoton akan membuat siswa bosan sehingga malas dalam kegiatan pembelajaran (Dewi dan Septa, 2019). Penggunaan media video dalam proses pembelajaran akan merangsang penglihatan dan pendengaran peserta didik sehingga mereka lebih focus belajar. Di sisi lain, media video dapat memaparkan tahapan-tahapan kerja praktek yang akandilakukansehinggapesertadidiklebihterarahdanmencapaihasil yang diinginkan. Serta memperjelas informasi belajar yang disampaikan guru kepada peserta didik agar tidak terlalu verbalistis, serta memperjelas proses pembelajaran berlangsung lebih efektif dan efisien. Sehingga akhirnya kreatifitas peserta didik secara tidak langsung meningkat. Pentingnya meningkatkan kemampuan siswa dalam pembelajaran matematika juga karena matematik merupakan tolak ukur dari perkembangan ilmu pengetahuan dan teknologi (Ulfa, 2019).

Media audio-visual, adalah jenis media yang digunakan dalam kegiatan pembelajaran dengan melibatkan pendengaran dan penglihatan sekaligus dalam satu proses atau kegiatan. Pesan dan informasi yang dapat disalurkan melalui media ini dapat berupa pesan verbal dan nonverbal yang mengandalkan baik penglihatan maupun pendengaran. Media pembelajaran berupa video ini sangatlah berpengaruh banyak untuk dunia pendidikan. Dibuktikan dari penelitian Chalid (2017) penerapan media berbasis video dapat meningkatkan hasil belajar siswa secara signifikan dengan pencapaian ketuntasan belajar yang diharapkan secara klasikal telah melampaui $75 \%$.

\section{METODE}

Metode penelitian yang digunakan dalam penelitian ini adalah metode deskriptif. Penelitian ini dimaksudkan untuk menggambarkan secara sistematik karakteristik objek atau subjek yang diteliti. Penelitian ini berfokus pada media pembelajaran audio visual atau video.

Penelitian ini melibatkan 5 siswa, guna mengembangkan sebuah media pembelajaran berupa video yang dilakukan pertama kali dengan mencari konsep sesuai dengan kompetensi dasar materi persamaan garis lurus untuk dijadikan data dalam membuat media pembelajaran. Setelah kita memenuhi semua data yang akan di gunakan untuk membuat media pembelajaran, selanjutnya kita mengolah data tersebut untuk dijadikan sebuah media dengan 2 tahap yaitu, rancangan design menggunakan power point untuk tahapp engolahan data pertama dan menjadikannya sebuah video, lalu tahap yang kedua ialah pengisian suara pada video agar video dapat digunakan untuk menjelaskan materi dan melengkapi video pembelajaran kita. 
Sesudah kita membuat media pembelajaran, selanjutnya kita akan memvalidasi dan revisi. Validasi dilakukan oleh ahli pada bidang konten. Tahap ini dilakukan untuk mengetahui apakah media yang telah dibuat sudah sesuai dengan indikator media yang layak.

\section{HASIL DAN PEMBAHASAN}

Penelitian ini merupakan pengembangan sebuah media pembelajaran yang diharapkan dapat membantu siswa dalam proses pembelajaran. Dalam media pembelajaran ini materi yang digunakan adalah persamaan garis lurus. Persamaan garis lurus meliputi konsep persamaan garis lurus, grafik persamaan garis lurus, dan gradien.

Tabel 1. Proses Perancangan

\begin{tabular}{|c|c|c|}
\hline Menentukkan KD & Menentukan Indikator & Membuat Materi \\
\hline $\begin{array}{ll}\text { Menganalisis fungsi } \\
\text { linear dan } \\
\text { menginterpretasikan } \\
\text { grafiknya yang } \\
\text { dihubungkan dengan } \\
\text { masalah kontekstual } \\
\text { Menyelesaikan } \\
\text { masalah kontekstual } \\
\text { yang berkaitan } \\
\text { dengan linear sebagai } \\
\text { persamaan garis } \\
\text { lurus. } \\
\end{array}$ & $\begin{array}{ll}\text { - } & \text { Mendeskripsikan pengertian } \\
& \text { persamaan garis lurus } \\
\text { - } & \text { Menggambar grafik dari } \\
& \text { persamaan garis lurus. } \\
\text { - } & \text { Konsep gradien persamaan garis } \\
\text { - } & \text { Menentukkan nilai dari gradien } \\
& \text { titik 1 dan gradien titik } 2 .\end{array}$ & $\begin{array}{l}\text { Persamaan Garis } \\
\text { Lurus } 1\end{array}$ \\
\hline
\end{tabular}

Setelah tahap membuat video media pembelajaran ini selesai, diperlukan validasi oleh ahli konten dan revisi untuk mengetahui apakah media pembelajaran kita dapat dipakai atau tidak serta revisi yang akan membantu kita dalam mengembangkan media pembelajaran kita.

Tabel 2. Hasil Validasi dan Revisi

\begin{tabular}{|l|l|}
\hline Validasi 1 & $\begin{array}{l}\bullet \\
\bullet\end{array}$ \\
\hline Revisi 1 & $\begin{array}{l}\text { Sudahdiperbaiki } \\
\bullet \quad \text { Video } \\
\text { sudahjelasdanlatihansoalmudahdimengerti }\end{array}$ \\
\hline Validasi 2 & $\bullet \quad$ Memperbaikisedikitmateri. \\
\hline Revisi 2 & $\begin{array}{l}\text { Sudahdiperbaiki } \\
\bullet \quad \text { Materisudahmudahdimengerti }\end{array}$ \\
\hline
\end{tabular}

Setelah melakukan pembuatan video media pembelajaran dan sudah melakukan validasi terhadap ahli konten serta melakukan revisi dan perbaikan media pembelajaran, video dapat di uji. Untuk mengetahui tingkat keberhasilan penerapan media pembelajaran ini, makadilakukan pengujian terhadap beberapa anak SMP kelas 8. Hasil yang diperoleh adalah siswa mampu memahami materi dengan baik, dan mampu menjelaskan kembali materi itu pada siswa lain. Siswa juga mampu mengerjakan kembali soal yang pemateri berikan seperti pada aktivitas yang dilakukan pada Gambar 1.

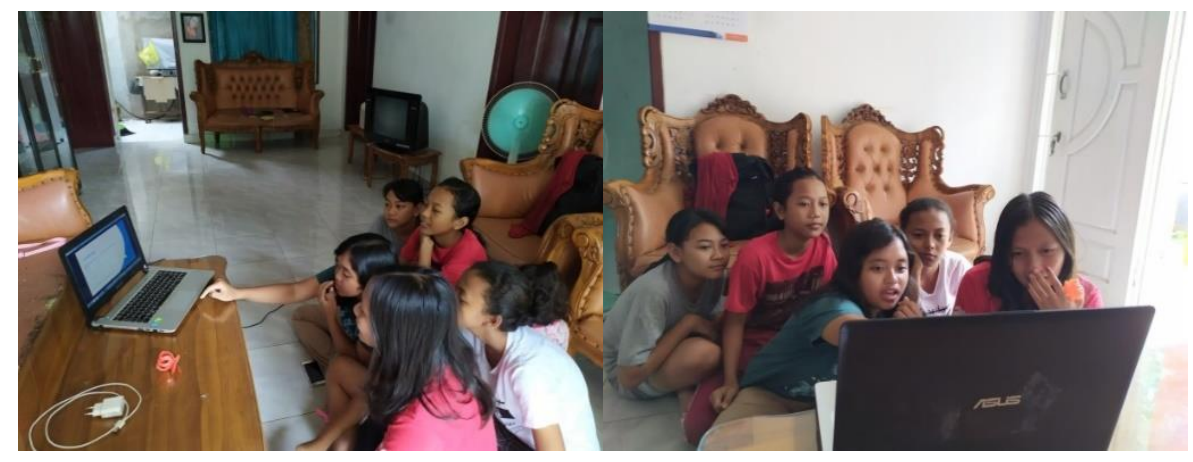

Gambar 1. Aktivitas Siswa pada Perkuliahan Daring 
Setelah siswa melihat video dan mempelajari materi yang ada pada video, pemateri melakukan wawancara terhadap 5 siswa atau siswi tersebut tentang pemahaman mereka tetang video dan apa yang menjadi kendala mereka dalam memahami video pembelajaran itu. Sehingga beberapa siswa menjelaskan bahwa video pembelajaran ini mudah dipahami dan ketepatan durasi dalam menjelaskan materi juga baik, latihan soal yang ada dalam video juga mudah dipahami dan pemberian gambar dan suara pada video juga membantu mereka dalam memahami. Ada 1atau 2 siswa juga yang belum sepenuhnya memahami karena tingkat pemahaman yang kurang serta kurangnya niat dalam belajar matematika.

\section{SIMPULAN}

Setelah melakukan pengujian pada beberapa siswa dapat disimpulkan bahwa media pembelajaran ini dapat digunakan untuk meningkatkan daya pikir yang kognitif serta mengembangkan pemahaman tentang materi persamaan garis lurus. Ada beberapa saran dari peserta didik untuk lebih lagi meningkatkan media pembelajaran ini dengan menambahkan banyak soal latihan yang lebih mudah dipahami lagi.

\section{REFERENSI}

Chalid, 2017. Metode Penelitian. Jakarta: Bumi Aksara

Dewi, P.S., \& Septa, H.W. (2019). Peningkatan Kemampuan Pemecahan Masalah dan Disposisi Matematis Siswa dengan Pembelajaran Berbasis Masalah. Mathema: Journal Pendidikan Matematika. 1(1), 31-39.

Maskar, S. \& Anderha, R. R. (2019). Pembelajaran Transformasi Geometri dengan Pendekatan Motif Kain Tapis Lampung. Mathema: Jurnal Pendidikan Metematika. 1(1), 40-47

Puspaningtyas, N. D. (2019). Berpikir Lateral Siswa SD dalam Pembelajaran Matematika. Mathema: Jurnal Pendidikan Matematika. 1(1), 25-30

Rohani. (1997). Media intruksionalEdukatif. Jakarta: PT Rineka Cipta.

Sadiman, dkk. (2009). Media Pendidikan, Pengertian, Pengembangan, danPemanfaatannya. Jakarta: Rajawali Press.

Saputra, V. H. \& Febriyanto, E. (2019). Media Pembelajaran Berbasis Multimedia Untuk Anak Tuna Grahita. Mathema: Jurnal Pendidikan Matematika. 1(1), 15-23

Ulfa, M. (2019). Strategi Preview, Question, Read, Reflect, Recite, Review (PQ4R) pada Pemahaman Konsep Matematika. Mathema Journal Pendidikan Matematika. 1(1), 48-55.

Yusuf. (2011). Psikologi Perkembangan Anak dan Remaja. Bandung: PT. Remaja Rosdaka 